\title{
The effect of connecting reading and writing in foreign language teaching in the computer mediated communication environment
}

\author{
Wang Ying
}

School of Foreign Languages and Literature Shandong University Jinan, China

\begin{abstract}
This paper reports a study investigating the effects of connecting reading and writing in Chinese EFL teaching in the computer-mediated communication (CMC) learning environment. In this study, ways of reading which are likely to promote the development of writing ability are sought and tested. What the subjects in the experimental group and the control group did is almost the same except that subjects in the experimental group are asked to write a 400-word summary or reviews after they finish learning each text while those in the control group are not. Results show that connecting reading and writing has positive effects on helping the students to memorize the new words, reusing new words in their writing tasks and improving the students' writing quality.
\end{abstract}

Index Terms: connecting reading and writing; EFL writing; CMC; EFL teaching and learning

(C) 2012 Published by MECS Publisher. Selection and/or peer review under responsibility of the International Conference on E-Business System and Education Technology

\section{Introduction}

Information technology combined with the advanced teaching and learning theories has made it possible to view foreign language learning and teaching from a new angle. With the use of computer and communication of the network, English language teaching and learning has gained a brand-new form and meaning.

The key interest in the computer-mediated communication (CMC), from an interactionist perspective on L2 learning, involves the specific ways in which CMC is relevant to and facilitative of the processes believed to be good to second language acquisition (SLA). Among the most important issues is establishing the facility of CMC to supply rich input, promote pushed output (Swain, 1995), provide plentiful and dynamic feedback, focus learners' attention on aspects of the target language, and enhance noticing [1]. Warschauer (1996), for example, found that it was more likely for students to pursue idea-generating discourse and they were less inhibited during written production than in oral discussion [2]. There is some indication that the text-based CMC medium can amplify students' attention to linguistic form by providing learners sufficient opportunity to notice lexical and grammatical features in the input [3].

$\mathrm{CMC}$, then, seems to be a favorable setting through which to test the effect of connecting reading and writing in the foreign language teaching and learning. Through this medium, the present study seeks to provide additional evidence for the positive role of connecting reading and writing in foreign language development by

* Corresponding author.

E-mail address: ywang@sdu.edu.cn 
examining the effects of connecting reading and writing in connection with learners' ability to subsequently produce target lexical items with which the tasks were seeded and their subsequent writing ability.

How to help English as a foreign language (EFL) learners develop their writing ability has been a big concern and a hot research focus in the research on second language acquisition. Recently the role or importance of reading in developing writing ability has been acknowledged (Hirvela, 2004). According to Carson and Leki (1993), reading is nearly always the basis for writing in academic settings [4]. Hirvela (2004) holds that reading supports writing through "meaningful input". According to Hirvela, reading and writing abilities share various constructs such as rhetorical structure, linguistic features of writing, and examining lexical as well as stylistic characteristics of writing [5]. While reading and writing have a lot to share and may support each other, there are differences between the two abilities, and reading ability does not always transfer to writing ability. As is known, the main goal of reading is to reflect on meaning and to understand writer's text and intention, reflecting on language is very important in writing to make sure that ideas are expressed appropriately. Students who anticipate writing are ready to shift their attention toward useful input for their future writing from the instructions.

Among the EFL learners, it is not always the case that good readers develop into good writers. Especially in China, there is a big room of differences between students' reading and writing ability. In pother words, many students develop into very competent readers without developing their writing ability to the same degree. How to promote students' writing ability in China-specific context becomes a big concern. How to facilitate students to use and reuse the rhetorical and linguistics conventions learned from the reading practice becomes a research interest in the area of foreign language teaching and research. In this study, ways of reading which are likely to promote the development of writing ability in the computer mediated communication learning environment is explored.

\section{Methodology}

In this study, computer (including information and network technology), classroom teaching and English courses are integrated with each other. The use of multimedia technology in the language classroom teaching involves the integration of data, graphics, text, sound, animation, images etc with teaching content. Effects of connecting reading and writing were investigated by the following two research questions:

1. What is the effect of connecting reading and writing in helping students to learn new words by heart?

2. What is the difference of writing quality between the experimental group and the control group?

\section{A. Subjects}

Subjects for this research were 50 third-year English majors in two parallel classes at a Chinese key university. Students in these two intact classes are randomly selected into two groups. One class would serve as the experimental group (EG) and the other class would serve as the control group (CG). There were 25 students in each group.

\section{B. Research Procedures}

A within groups and between groups pretest-posttest design was employed. The subjects met once a week in a campus computer-mediated classroom during regularly scheduled class meeting time over a 16-week period. After the detailed study of the text, including the knowledge at lexical, grammar, discourse levels presented by PPT and the finishing doing the exercises in the textbook. Fifty new words from each lesson were chosen and explained by the teacher one by one through the PPT presentation. All these exercises help the learners to grasp and understand the text better. Usually it takes two or three weeks to learn a lesson. For the two groups, their teacher, textbooks, curriculum, teaching plan, aims and objectives are the same. At the very end of last class for

Supported by Shandong Social Science Planning and Research Project (08BWXZ01) and Independent Inno vation Foundation of Shandong

University and Teaching Reform Project of Shandong University. 
each lesson, subjects in the experimental group are assigned the writing task to write a relate essay or summary or a critical comment after finishing learning each lesson in their after-class time. Altogether 7 essays (summaries or comments) in at least 400 words were written during this 16-week semester.

In the pre-test, subjects were given 50 sentences, and there was one new word in each sentence (one new word being 1 score) randomly selected from the text. Subjects were asked to translate the 50 sentences into Chinese to see whether there was any difference between the two groups in their memory work. After their vocabulary test, subjects were asked to write summaries or comments and also asked to use new words they learned as possible as they can. The total score for the writing task is 100 scores. The procedures for the post-test are the same as those for the pre-test.

These subjects can send their essays to their English teacher by email and get the teacher's feedback via email. The research/author makes all comments on the computer by using "track changes" and "insert comments" of Microsoft Word. Comments are inserted electronically via Word's "insert comments" feature, and changes are made to the papers via Word's "track changes" feature. Marginal comments are typed into the paper, and end comments are made regarding the paper. All the students received comments from their teacher on their first drafts and used those comments to make their second drafts.

\section{Data collection and analysis}

Data were collected throughout the 16-week course of the semester. Two data sources were used: vocabulary tests for EG and CG in the pre-test and post-test and essays of subjects in the pre-test and post-test.

Written data consisted of all the writing tasks carried out by the students during 16-week course, including drafts and revised versions of written assignments, together with teacher written feedback. In rating the essays of subjects in the pre-test and post-test, inter-rater reliability was found to be 0.87 and 0.85 (Pearson productmoment correlation coefficient).

Independent Sample t-tests are used to see whether there was a significant difference between number of new words used in vocabulary pre-test and vocabulary post-test. And also Independent Sample t-tests are used to see whether there is any difference between number of new words used in the essays of subjects in the pre-test and post-test. The holistic rating was employed to determine whether there was a significant difference in quality of writing produced by the EG and CG in the pre-test and post-test.

\section{Results and discussion}

In order to determine whether there was a significant difference between the experimental and control groups at the beginning of the test, independent samples t-test was used to compare the mean scores of the two groups with respect to the new words that the subjects can use in the vocabulary pre-test. The results of the independent samples t-test for the EG and the CG vocabulary test are shown in Table 1.

TABLE I. RESULTS OF INDEPENDENT SAMPLE T-TEST FOR EG AND CG VOCABULARY TESTS

\begin{tabular}{|c|c|c|c|c|c|c|}
\hline & \multicolumn{2}{|c|}{ EG (n=25) } & \multicolumn{2}{c|}{ CG (n=25) } & & \\
\cline { 2 - 7 } & $\boldsymbol{M}$ & $\boldsymbol{S D}$ & $\boldsymbol{M}$ & $\boldsymbol{S D}$ & $\boldsymbol{t}$ & $\boldsymbol{p}$ \\
\hline $\begin{array}{c}\text { Number of new } \\
\text { words used in } \\
\text { Vocabulary pre-test }\end{array}$ & 37.13 & 3.76 & 37.52 & 3.07 & -0.39 & 0.70 \\
\hline $\begin{array}{c}\text { Number of new } \\
\text { words used in } \\
\text { Vocabulary post-test }\end{array}$ & 39.91 & 3.33 & 37.96 & 3.26 & 2.02 & 0.05 \\
\hline
\end{tabular}


The result reveals that the difference between the $\mathrm{EG}(\mathrm{M}=37.13, \mathrm{SD}=3.76)$ and the $\mathrm{CG}(\mathrm{M}=37.52, \mathrm{SD}=3.07)$ on the number of the new words used in pre-test is not significant $(t=-.39 ; \mathrm{p}=.70)$. This indicates that the two groups were at roughly the same level with regard to their vocabulary level at the beginning of the semester. Therefore, the differences found in the following analysis may be attributed, with a certain degree of certainty, to experiment effects.

The result of independent samples t-test demonstrates that there is significant difference between the EG and the $C G$ on the number of the new words used in post-test $(t=2.02 ; p=.05)$. Since the two groups were at roughly the same level with regard to their vocabulary level at the beginning of the semester, the differences found in the analysis may be attributed, with a certain degree of certainty, to treatment effects. That is to say, the EG made significant progress within the period within which the experiment was being conducted.

TABLE II.

RESULTS OF THE NUMBER OF NEW WORDS USED IN WRITING FOR EG AND CG

\begin{tabular}{|c|c|c|c|c|c|c|}
\hline & \multicolumn{2}{|c|}{ EG (n=25) } & \multicolumn{2}{|c|}{ CG (n=25) } & & \\
\cline { 2 - 7 } & $\boldsymbol{M}$ & $\boldsymbol{S D}$ & $\boldsymbol{M}$ & $\boldsymbol{S D}$ & $\boldsymbol{t}$ & $\boldsymbol{p}$ \\
\hline $\begin{array}{c}\text { Number of new } \\
\text { words used in } \\
\text { Writing 1 }\end{array}$ & 13.61 & 2.94 & 13.87 & 3.37 & -0.28 & 0.78 \\
\hline $\begin{array}{c}\text { Number of new } \\
\text { words used in } \\
\text { Writing 2 }\end{array}$ & 16.48 & 3.59 & 14.35 & 3.45 & 2.05 & 0.04 \\
\hline
\end{tabular}

The result (see Table 2) reveals that the difference between the EG $(M=13.61, S D=2.94)$ and the CG $(\mathrm{M}=13.87, \mathrm{SD}=3.37)$ on the number of the new words used in Writing task 1 in pre-test is not significant ( $\mathrm{t}=-.28$; $\mathrm{p}=.78$ ). This indicates that the two groups were at roughly the same level with regard to their vocabulary level at the beginning of the semester.

The result of independent samples t-test (see Table 2) demonstrates that there is a significant difference between the EG and the CG on the number of the new words used in post-test $(t=2.05 ; \mathrm{p}=.04)$. Since the two groups were at roughly the same level with regard to their vocabulary level at the beginning of the semester, the differences found in the analysis may be attributed, with a certain degree of certainty, to treatment effects. That is to say, the EG outdid the CG within the period within which the experiment was being conducted.

TABLE III. RESULTS OF INDEPENDENT SAMPLE T-TEST FOR EG AND CG HOLISTIC SCORES

\begin{tabular}{|c|c|c|c|c|c|c|}
\hline & \multicolumn{2}{|c|}{ EG $(\mathbf{n = 2 5})$} & \multicolumn{2}{c|}{ CG (n=25) } & & \\
\cline { 2 - 7 } & $\boldsymbol{M}$ & $\boldsymbol{S D}$ & $\boldsymbol{M}$ & $\boldsymbol{S D}$ & $\boldsymbol{t}$ & $\boldsymbol{P}$ \\
\hline $\begin{array}{c}\text { Holistic scores } \\
\text { for writing task 1 }\end{array}$ & 79.08 & 5.47 & 78.76 & 6.81 & 0.18 & 0.86 \\
\hline $\begin{array}{c}\text { Holistic scores } \\
\text { for writing task 2 }\end{array}$ & 82.80 & 3.99 & 80.00 & 4.87 & 2.22 & 0.03 \\
\hline
\end{tabular}

The result (see Table 3) reveals that the difference between the EG $(M=79.08, S D=5.47)$ and the CG $(\mathrm{M}=78.76, \mathrm{SD}=6.81)$ on writing task 1 is not significant $(\mathrm{t}=.18 ; \mathrm{p}=.86)$. This indicates that the two groups were at roughly the same level with regard to their writing level at the beginning of the semester.

The result of independent samples t-test (see Table 3) demonstrates that there is a significant difference between the EG and the CG on writing task $2(\mathrm{t}=2.22 ; \mathrm{p}=.03)$. Since the two groups were at roughly the same level with regard to their writing quality at the beginning of the semester, the differences found in the analysis may be attributed, with a certain degree of certainty, to treatment effects. That is to say, the EG outdid the CG in writing quality within the period within which the experiment was being conducted. 
Students in the EG made significantly high-quality writing than those in the CG at the end of the semester. When students in the EG wrote relate summaries or comments after learning each text, they had the chances to use language rather than just study it. Students built in recycling and repetition of words and grammar structures and had the chances to deepen and consolidate the language they just learned in their textbook. Students in the EG outdid those in the CG in memorizing the new words they just learned. In the summaries or comments written by the students in the EG, the new words they just learned occurred at a significantly high percentage than those in the summaries written by the students in the CG. All this shows that in their writing practice and progress, students develop their own sense of how the language works. As Swain (1985) points out that producing the target language may be the trigger that forces the learner to pay attention to the means of expression needed in order to successfully convey his or her own intended meaning. In order to make the directions in the specific for repeated use, students are likely to shift conscious attention to important words, phrases or collocations for understanding the content of the text or for identifying the rhetorical information, form of words and grammatical structure.

\section{Conclusion}

The results of the 16-week experiment show that connecting reading and writing has positive effects on helping the students to memorize the new words, the reuse of new words in their writing tasks and improving the students' writing quality. In producing the target language, students are given the chances to see how the vocabulary and grammar are used together to express the intended meaning. Finally, the author believes that the findings of the study has demonstrated the EFL learners can improve their memory of vocabulary, their reuse of vocabulary and writing quality if they are given the chances to use the language rather than just study it.

\section{References}

[1] G. Cook and B. Seidlhofer, Principles and Practice in Applied Linguistics: Studies in Honor of H.G. Widdowson. Oxford: Oxford University Press, 1995.

[2] M. Warschauer, Telecollaboration in Foreign Language Learning. Honolulu, Hawaii: Second language Teaching \& Curriculum Centre, 1996.

[3] M. Warschauer, and R. Kern, Network-Based Language Teaching: Concepts and Practice. Cambridge: Cambridge University Press, 2000.

[4] J. Carson, and I. Leki, Reading in the composition classroom: Second language perspective. Boston: Heinle \& Heinle, 1993.

[5] A. Hirvela, Connecting reading \& writing in second language writing instruction. Ann Arbor, MI: The University of Michigan Press, 2004 